\title{
Pitfalls in counselling of the blepharophimosis, ptosis, epicanthus inversus syndrome (BPES)
}

\author{
I K TEMPLE AND M BARAITSER \\ From the Hospitals for Sick Children, Great Ormond Street, London WC1N 3JH.
}

SUMmaRY Non-penetrance or minimal expression as a genetic counselling problem in the blepharophimosis syndrome is discussed.

In a recent 'Syndrome of the month', Oley and Baraitser ${ }^{1}$ drew attention to some of the counselling problems in the dominantly inherited blepharophimosis, ptosis, epicanthus inversus syndrome. The first concerns the subdivision into types I and II based on the suggestion that type I is transmitted by males only, as affected females are infertile. ${ }^{2}$ Without a suitably sized pedigree, classification is not possible and genetic counselling of affected females can be a problem. The second difficulty, again mentioned by Zlotogora et $a l^{2}{ }^{2}$ is that whereas type I is totally penetrant, type II has a penetrance of $96.5 \%$. These figures suggest that the condition is almost totally penetrant, but we wish to report a family in which a mistake could easily be made as a reminder of the difficulties in counselling such families.

\section{Case report}

A male patient (III.1, fig 1) was born at 37 weeks' gestation with a normal birth weight $(3300 \mathrm{~g})$ after a forceps delivery. There were no neonatal problems but examination at birth showed he had hypertelorism, prominent epicanthic folds, and upward

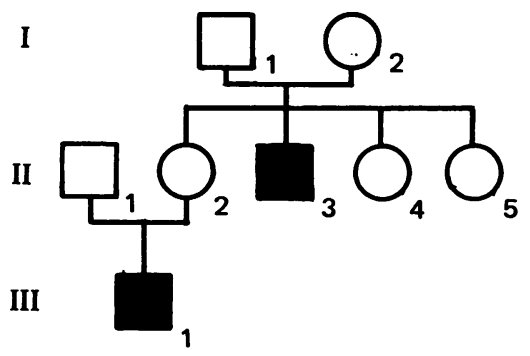

FIG 1 Family pedigree.

Received for publication 1 December 1988.

Revised version accepted for publication 13 March 1989. slanting palpebral fissures. It was noted by the nursing staff that he hardly opened his eyes and he subsequently was found to have marked ptosis. The other dysmorphic feature that was noted was that he had a small, upturned nose with anteverted nostrils. He also had a ventricular septal defect but this did not need treatment. He was seen at seven months when he was almost sitting. His mother said that his development was impeded by his having to tilt his head backwards in order to see (fig 2). At 18 months, the first operation was performed on his ptosis. Other parameters at 18 months were a height

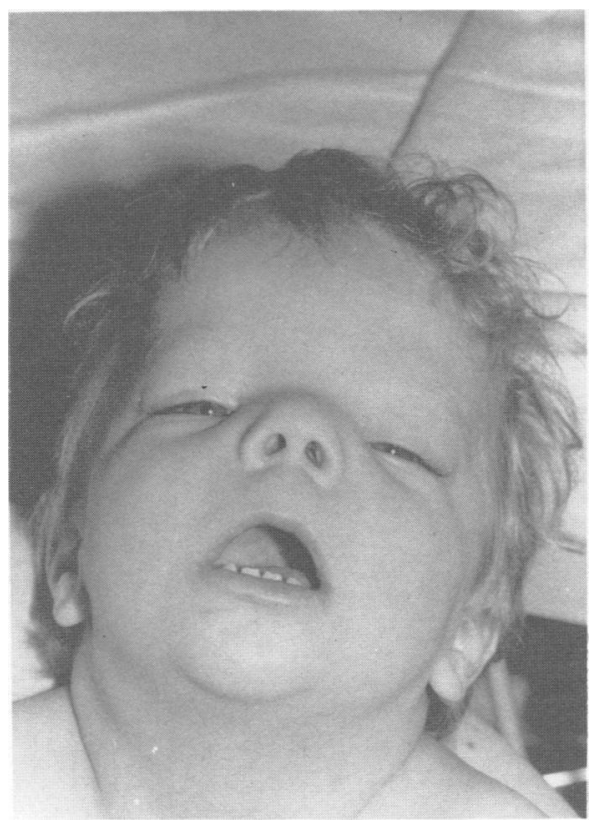

FIG 2 III.1 at seven months of age. Note the marked ptosis, upward slanting palpebral fissures, and small nose with anteverted nostrils. 
and weight just below the 3rd centile and a head circumference on the 50th centile. When tested formally at two years six months, his overall development was judged to be at the two year level. More recently, at the age of four years, his speech was progressing better than previously but he was still a little behind that expected. Further operations on his eyes are planned.

\section{Family history}

The family pedigree is shown in fig 1 .

The proband's mother (II.2) and father (II.1) were seen. They were of normal height, weight, and intelligence and in particular there was no evidence of ptosis nor of any vestige of an epicanthic fold (fig 3 ). Early pictures of the mother were studied and one is shown in fig 4. Minimal droop of the right eye was noted but it would have been concluded that the chances of her being a gene carrier were small. The mother stated at the interview that her brother II.3 had the same condition as her son.

II. 3 is $\mathbf{3 0}$ years of age and gave a history that his left eye did not open until he was two years of age and that he always had right sided ptosis (fig 5).

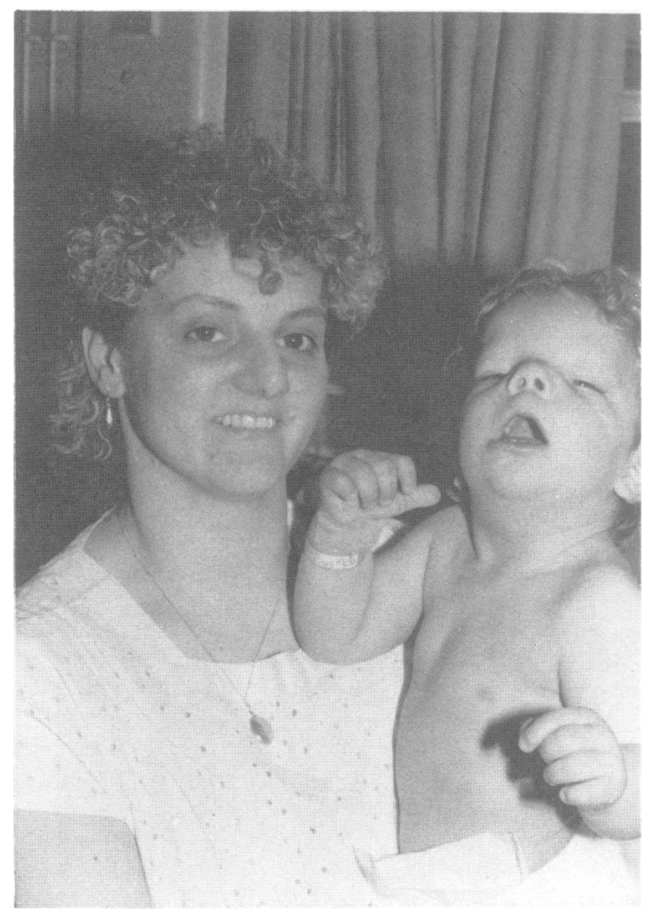

FG 3 Mother (II.2) and son (III.1). The mother has no evidence of blepharophimosis or ptosis as an adult.

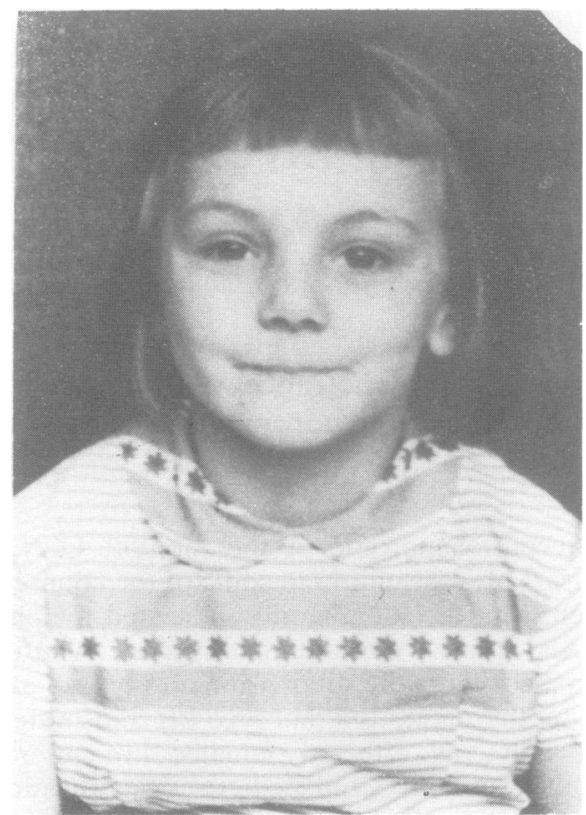

FIG 4 II. 2 as a child. There is minimal ptosis on the right but no evidence of epicanthus inversus.

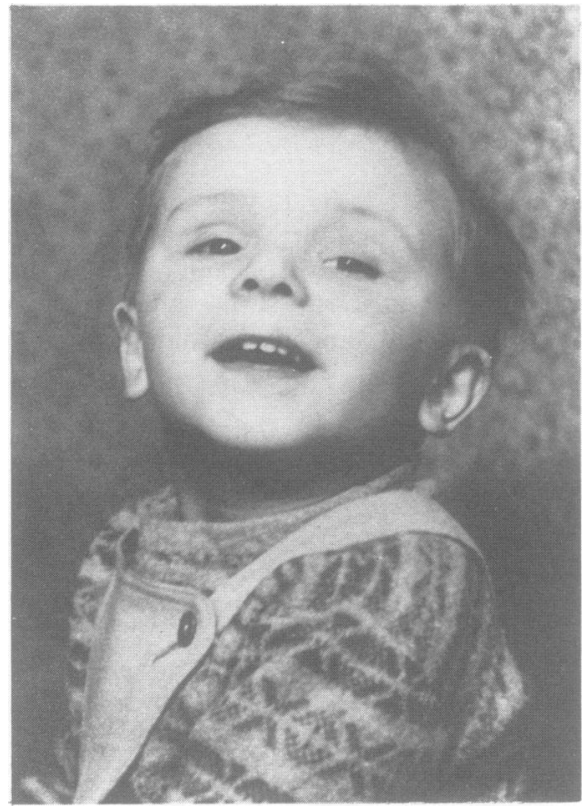

FIG $5 \quad I I .3$ as a child showing severe ptosis bilaterally and remarkable similarity to his nephew III.1. 


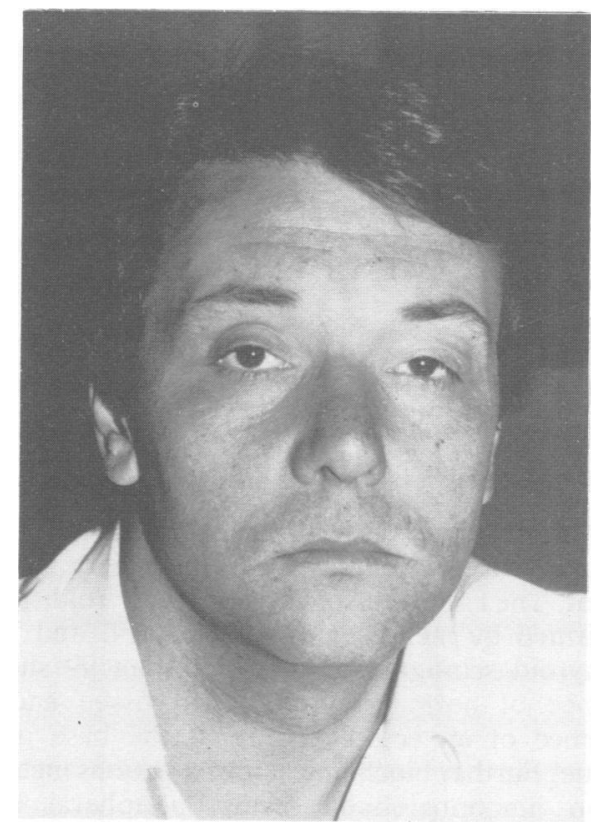

FIG 6 II.3 aged 30 years showing bilateral ptosis.

Since early childhood, there had been seven operative attempts to correct his congenital malformations, but when seen it was clear that he had ptosis and blepharophimosis. He had no other problems and intelligence was normal: A recent photograph is shown in fig 6.

I. 1 and I. 2 are reported to be normal.

\section{Discussion}

COUNSELLING PROBLEM

High recurrence risks in the BPES syndrome need to be taken seriously. The main problems consist of the difficulty of correcting the ptosis surgically, mild mental retardation in some cases, and female infertility. The enigma in this family is that the proband (III.1) and his maternal uncle (II.3) are affected but the mother herself has no obvious signs of eye involvement. There are two ways of interpreting the pedigree. The least likely is that it is $\mathrm{X}$ linked and that mother is a non-manifesting carrier, but this mode of transmission has not yet been described. It is more likely that we are dealing here with reduced penetrance or very minimal expression in the mother and we must assume that this has already occurred twice in the present family. Photographically, there is no evidence that mother's parents were affected although no early photographs are available, which prove particularly important in this condition. One of them must have been a gene carrier if dominant inheritance is to be postulated in this family.

Whatever the explanation, we would want to point out that genetic counsellors must be aware of non-penetrance or very minimal expression in this condition and be cautious about counselling very low offspring risks to unaffected members of these families.

\section{References}

${ }^{1}$ Oley C, Baraitser M. Blepharophimosis, ptosis, epicanthus inversus syndrome (BPES syndrome), J Med Genet 1988;25: 47-51.

2 Zlotogora J, Sagi M, Cohen T. The blepharophimosis, ptosis and epicanthus inversus syndrome: delineation of two types. $\mathrm{Am}$ J Hum Genet 1983;35:1020-7.

Correspondence to Dr I K Temple, Department of Clinical Genetics, Institute of Child Health, 30 Guilford Street, London WC1N IEH. 